Article

\title{
Exploring the Biodiversity of Red Yeasts for In Vitro and In Vivo Phenotypes Relevant to Agri-Food-Related Processes
}

\author{
Giacomo Zara, Maria Grazia Farbo (D), Chiara Multineddu (D), Quirico Migheli, Marilena Budroni (D), \\ Severino Zara (D) and Ilaria Mannazzu* \\ Department of Agricultural Sciences, University of Sassari, Viale Italia 39, 07100 Sassari, Italy; \\ gzara@uniss.it (G.Z.); mgfarbo@uniss.it (M.G.F.); c.multineddu@uniss.it (C.M.); migheli@uniss.it (Q.M.); \\ mbudroni@uniss.it (M.B.); szara@uniss.it (S.Z.) \\ * Correspondence: imannazzu@uniss.it
}

Citation: Zara, G.; Farbo, M.G.;

Multineddu, C.; Migheli, Q.; Budroni,

M.; Zara, S.; Mannazzu, I. Exploring

the Biodiversity of Red Yeasts for In

Vitro and In Vivo Phenotypes

Relevant to Agri-Food-Related

Processes. Fermentation 2021, 7, 2.

https://dx.doi.org/10.3390/

fermentation7010002

Received: 3 December 2020

Accepted: 21 December 2020

Published: 24 December 2020

Publisher's Note: MDPI stays neutral with regard to jurisdictional claims in published maps and institutional affiliations.

Copyright: () 2020 by the authors. Licensee MDPI, Basel, Switzerland. This article is an open access article distributed under the terms and conditions of the Creative Commons Attribution (CC BY) license (https: / / creativecommons.org/ licenses/by/4.0/).

\begin{abstract}
Red yeasts grow on food wastes, show antagonistic activity against food-spoilage microorganisms, produce food supplements, and may be utilized as feed-supplements themselves to positively modulate the quali-quantitative composition of intestinal microbiota. Therefore, they show a variety of possible biotechnological applications in agri-food-related processes. Here, to further explore the biotechnological potential of red yeasts, eleven strains ascribed to different species of the genera Rhodotorula and Sporobolomyces, differing for biomass and carotenoids production, were characterized in vitro for biofilm formation, invasive growth, and growth the temperature range of $20-40{ }^{\circ} \mathrm{C}$ and in vivo for their antagonistic activity against the fungal pathogen and patulin producer Penicillium expansum. Most of them formed cellular MAT and showed invasive growth as well as adhesion to plastic materials. Four strains determined a significant reduction of fruit decay caused by P. expansum on apple fruit while the remaining seven showed different degrees of biocontrol activity. Finally, none of them grew at body temperature $\left(>37^{\circ} \mathrm{C}\right)$. Statistical analyses of both qualitative and quantitative phenotypic data, including biomass and carotenoids production, gathered further information on the most interesting strains for the biotechnological exploitation of red yeasts in agri-food-related process.
\end{abstract}

Keywords: biofilm formation; biocontrol; Rhodotorula; Sporobolomyces; MAT

\section{Introduction}

Red yeasts, mainly ascribed to the genera Rhodotorula and Sporobolomyces within Pucciniomycotina, are well known producers of microbial oils, surfactants, and enzymes of interest for chemical and pharmaceutical industries and carotenoids [1-3]. In the food sector, the growing interest in the biotechnological exploitation of red yeasts is due to their production of carotenoids. These compounds have important biological properties such as antioxidant, photoprotective [4,5], and putative antitumor activities [6]. Accordingly, the demand for carotenoid-containing food products, such as red soy cheese, meat, alcoholic beverages, and by-products of meat and fish, is globally increasing (https:/ / www.factmr. com/report/1196/carotenoids-market, accessed on 1 December, 2020).

Even though carotenoids may be chemically synthesized, rising health concerns against artificial synthetic pigments render their production through microbial-based technologies particularly attractive. Of particular interest is the possibility to obtain these metabolites from by-products and wastes, thus increasing the sustainability of their production. In this respect, some of the red yeasts grow at high cell density on a plethora of different carbon and nitrogen sources and they are generally characterized by tolerance to inhibitory compounds present in growth substrates obtained from wastes of the food industry [7]. Moreover, red yeasts could be efficiently used for the bio-preservation of foods during storage. Rhodotorula mucilaginosa counteracts Penicillium expansum and Botrytis cinerea on apple [8] and Rhizopus sp. on strawberries [9]. Rhodotorula glutinis presents 
biocontrol activity against B. cinerea [10-12], P. expansum [13], Alternaria alternata [14], and Rhizopus stolonifer [15]. Similarly, Sporobolomyces roseus and Sporobolomyces kratochvilovae were described as possible biocontrol agents against $B$. cinerea and P. expansum, respectively, on apple fruit $[16,17]$. The mechanisms involved in yeast biocontrol activity have been elucidated, at least in part in a number of different species $[18,19]$. With respect to red yeasts, $S$. roseus was shown to antagonize $B$. cinerea by competing for nutrients [16], while Rhodosporidium toruloides and R. glutinis biocontrol activity is mediated by their attachment to B. cinerea through the involvement of cell wall glycoproteins [12,20]. Pandin et al. [21] indicated biofilm forming ability as one of the characters to be evaluated for a rapid screening of biocontrol agents. On the other hand, transition to a filamentous form of growth, which is required for both biofilm formation and invasive growth, has been correlated to yeast pathogenesis on immune-compromised individuals [22]. Thus, the evaluation of yeast ability to grow at the body temperature and to switch to an invasive form of growth is of particular importance given the fact that red yeast species have been proposed directly as feed supplements [23,24].

Due to their vast biotechnological potential, the molecular tools for heterologous genes expression in red yeasts were developed and, recently, an extensive study of the codon bias in these yeasts was carried out in view of the optimization of the heterologous gene sequences for transgene expression [25].

Here, in order to further explore the biotechnological potential of red yeasts, eleven Rhodotorula and Sporobolomyces strains already characterized for biomass and carotenoids production [26] were further characterized in vitro for biofilm forming ability, invasive growth and growth temperature interval, and in vivo for their antagonistic activity against P. expansum on apple.

\section{Materials and Methods}

\subsection{Microorganisms and Culture Media}

The Rhodotorula and Sporobolomyces strains utilized and their origins are reported in Table 1. Strain DiSVAC2.5t1 is deposited at the Industrial Yeast Collection of the University of Perugia, with accession number DBVPG 10619. DiSVA C71t0 belongs to the Yeast Collection of Dipartimento di Scienze della Vita e dell'Ambiente, Università Politecnica delle Marche. The remaining strains were purchased by Centraalbureau voor Schimmelcultures and the Industrial Yeast Collection of the University of Perugia. All strains were previously characterized for the production of biomass and carotenoids [26] and strain DiSVAC2.5t1 was subject to genomic $[27,28]$ and proteomic analyses [29].

Table 1. Yeast strains utilized.

\begin{tabular}{cc}
\hline Strain & Species \\
\hline DBVPG6091 & Rhodotorula mucilaginosa \\
DBVPG6094 & Rhodotorula mucilaginosa \\
DiSVAC2.5t1 & Rhodotorula mucilaginosa \\
DBVPG7019 & Rhodotorula mucilaginosa \\
DiSVAC71t0 & Rhodotorula mucilaginosa \\
CBS2366 & Rhodotorula glutinis \\
CBS2367 & Rhodotorula glutinis \\
CBS6016 & Rhodotorula toruloides \\
CBS315 & Rhodotorula toruloides \\
CBS7228 & Sporobolomyces oryzicola \\
CBS7998 & Rhodotorula cresolica \\
\hline
\end{tabular}

DBVPG: Industrial Yeast Collection, University of Perugia, Perugia, Italy; DiSVA: Yeast Collection of Dipartimento di Scienze della Vita e dell'Ambiente, Università Politecnica delle Marche, Ancona, Italy; CBS: Centraalbureau voor Schimmelcultures (CBS) Utrecht, The Netherlands.

Media used were YEPD: $1 \%$ yeast extract, $2 \%$ peptone, $2 \%$ glucose; YEPDagar: as YEPD added with agar at the percentage indicated in subscript; $\mathrm{SCD}_{2 \%}: 0.67 \%$ Yeast 
Nitrogen Base w/o amino acids, 2\% glucose; $\mathrm{SCD}_{0.1 \%}: 0.67 \%$ Yeast Nitrogen Base w/o amino acids, $0.1 \%$ glucose; SCGly: $0.67 \%$ Yeast Nitrogen Base w / o amino acids, 2\% glycerol.

\subsection{Adhesion to Plastic Materials}

Adhesion to plastic material was evaluated as described by [30]. Briefly, yeast strains were precultured in $50 \mathrm{~mL} \mathrm{SCD}{ }_{2}$ within $250 \mathrm{~mL}$ baffled flasks at $30^{\circ} \mathrm{C}$ under shacking conditions (180 rpm). After $12 \mathrm{~h}$ cells were centrifuged $(3000 \mathrm{rpm})$, washed and resuspended in sterile distilled water, and inoculated in $\mathrm{SCD}_{0.1 \%}$ to an $\mathrm{OD}_{600}$ of 1.0. Three replicates of $100 \mu \mathrm{L}$ aliquots of cell suspension were deposited in 96 wells microtiter polystyrene, polypropylene and polyvinyl chloride plates and incubated in static at $30{ }^{\circ} \mathrm{C}$. After $12 \mathrm{~h}$, $100 \mu \mathrm{L}$ of $1 \%$ crystal violet was added to each well and after $20 \mathrm{~min}$ wells were rinsed repeatedly with sterile distilled water and dabbed with absorbent paper. A total of $100 \mu \mathrm{L}$ 0.1 SDS was added to each well and, after $25 \mathrm{~min}$ at $25^{\circ} \mathrm{C}$, all samples were transferred to a new microtiter plate to evaluate absorbance at $570 \mathrm{~nm}\left(\mathrm{Abs}_{570}\right)$ and $590 \mathrm{~nm}\left(\mathrm{Abs}_{590}\right)$. Saccharomyces cerevisiae strains UNISSM25 (MATa/MATa HO/HO HMRa/HMRa HMLa/HMLa) and UNISS3238-32 fflo11 (MAT $\alpha$ leu2-1 lys2-801 flo11 $:: U R A 3$ ura3-52), whose adhesion to plastic materials had already been described [31,32], were utilized as positive and negative controls of adhesion, respectively. Both strains belong to the Microbial Culture Collection of the University of Sassari, Sassari, Italy.

\subsection{Cell MAT Formation}

Cell MAT formation was evaluated by inoculating $5 \mu \mathrm{L}$ of cell suspensions $\left(\mathrm{OD}_{600} 0.5\right)$ in the center of Petri dishes containing $\mathrm{YEPD}_{0.3 \%}, \mathrm{YEPD}_{2} \%, \mathrm{YEPD}_{4 \%}$. At least three replicates for each plate were prepared. The plates were incubated with yeast inoculum side up for 15 days at $25^{\circ} \mathrm{C}$ after which cell MATs were photographed with a digital camera.

\subsection{Invasive Growth}

One-mL aliquots of yeast cultures inoculated in $\mathrm{SCD}_{2} \%$ and incubated for $12 \mathrm{~h}$ at $180 \mathrm{rpm}$ at $30{ }^{\circ} \mathrm{C}$ were centrifuged at $14,000 \times g 1 \mathrm{~min}$ a $20^{\circ} \mathrm{C}$. The cell pellet was resuspended in $1 \mathrm{~mL}$ sterile distilled water to $\mathrm{OD}_{600}$ of 0.5 and $10 \mu \mathrm{L}$ aliquots were spotted on $\mathrm{SCD}_{0.1 \%}$ and incubated at $25^{\circ} \mathrm{C}$. After 10 days, each plate was photographed with a digital camera before and after washing with sterile distilled water.

\subsection{Growth at Different Temperatures}

Growth at different temperatures was evaluated by means of spot assay on $\mathrm{YEPD}_{2} \%$, incubated at $20,25,30,35$, and $37^{\circ} \mathrm{C}$. Briefly, yeast strains were precultured in $\mathrm{YEPD}_{2} \%$ and a small aliquot of cell biomass was diluted in sterile distilled water to $\mathrm{OD}_{600}$ of 5 . Cell suspensions were serially diluted $\left(10^{-1}, 10^{-2}, 10^{-3}, 10^{-4}\right)$ and $4 \mu \mathrm{L}$ of each dilution were seeded on agar medium. Yeast growth was evaluated after $48 \mathrm{~h}$.

\subsection{Biocontrol In Vivo}

Apple fruits (Malus domestica Borkh. cvs Golden Delicious) were washed with sodium hypochlorite $(0.8 \%$ as chlorine), rinsed with tap water, and air dried. Three wounds ( $3 \mathrm{~mm}$ depth) were engraved with a sterile micropipette tip at the equatorial region of each fruit and $1 \times 10^{6}$ yeast cells were inoculated into each wound. After $2 \mathrm{~h}$ at $26^{\circ} \mathrm{C}$, each wound was inoculated with by pipetting $10 \mu \mathrm{L}$ of a conidial suspension of P. expansum $\left(1 \times 10^{6}\right.$ conidia $\left./ \mathrm{mL}\right)$. A negative control of infection was set by pipetting $20 \mu \mathrm{L}$ of sterile Ringer solution into each wound. To confirm the pathogenicity of the fungal strain, a positive control was obtained by pipetting $10 \mu \mathrm{L}$ of Ringer solution and after $2 \mathrm{~h} 10 \mu \mathrm{L}$ of a conidial suspension of $P$. expansum. Upon air drying, the fruits were placed in plastic holders $(60 \mathrm{~cm} \times 40 \mathrm{~cm} \times 15 \mathrm{~cm}$, one layer), wrapped in transparent polyethylene bags to prevent evaporation, and stored in the dark at $26{ }^{\circ} \mathrm{C}$ and $85 \pm 5 \%$ relative humidity. The diameter of decayed tissue around each wound was measured at $48 \mathrm{~h}$ intervals to evaluate the incidence of $P$. expansum infection. There were 9 apples per treatment, the 
treatments were arranged in a completely randomized block design, and each experiment was repeated three times. Results are expressed as percentage of decay reduction (means \pm standard deviation of three independent replicates of three biological samples) with respect to the inoculated control after 7 days of incubation.

\subsection{Statistical Analysis}

The significance of differences among quantitative phenotypic data was assessed using one-way ANOVA, followed by multiple comparison by Dunnett's test $(p<0.05)$, using Minitab ${ }^{\circledR}$ for Windows release 12.1 (Minitab LLC, State College, Pennsylvania, USA). For each yeast strain, the significance of difference in the diameter of decayed tissue of the inoculated sample with respect to the control, was assessed by $t$-test $(p<0.05)$. To analyze the similarity between the tested yeast strains, a factor analysis of mixed data (FAMD) was carried out by taking into account both qualitative and quantitative phenotypic variables. To get further insights into the similarities between observations, the factors derived out of FAMD where used to conduct a k-means cluster analysis. All the calculations were carried out using the R software ver. 3.6.3 (The R Foundation for Statistical Computing, Vienna, Austria) and the R-packages "FactoMineR" [33] and "factoextra" [34].

\section{Results and Discussion}

\subsection{Biofilm Forming Ability}

The ability of yeast to form biofilm on biotic and abiotic surfaces is a phenotypic character with both negative and positive implications. It is undesired within the clinical realm [35-37] but also in food processing and drinking water distribution systems [38-40]. In contrast, biofilm formation is required in some food processes including the maturation of cheeses and sausages [41-43] and the biological aging of wine [44]. In addition, biofilm forming ability is required for the cleaning up of hazardous waste sites [45] and for heavy metal removal [46].

Since in S. cerevisiae biofilm forming ability is investigated through the evaluation of cellular MAT formation and adhesion to plastic materials [30], these phenotypes were analyzed in 11 red yeasts of different origins (Table 1). Cellular MAT formation, which refers to the production of large colonies on the surface of low density agar [47], was evaluated onto $\mathrm{YEPD}_{0.3 \%}, \mathrm{YEPD}_{2} \%$, and $\mathrm{YEPD}_{4 \%}$ [48]. According to [48], on $\mathrm{YEPD}_{0.3 \%}$, it is possible to observe colony spreading and the formation of the radial spoke pattern. On $\mathrm{YEPD}_{2 \%}$, the architecture of MAT is revealed while on $\mathrm{YEPD}_{4 \%}$, dense and complex MAT with ruffling morphology may appear. With the exception of $R$. glutinis CBS2367, all strains produced cellular MAT on $\mathrm{YEPD}_{0.3 \%}$ (Figure 1) with variable colony expansion and architecture. In particular, $R$. mucilaginosa DBVPG6091, DiSVAC71t0, and DiSVAC2.5t1, S. oryzicola CBS7228 and R. cresolica CBS7998 formed wide MATs (diameter $\geq 4 \mathrm{~cm}$ ) with a smooth hub and a peripheral smooth ring. $R$. mucilaginosa DBVPG7019 and $R$. toruloides CBS315 produced smaller MATs (diameter $3.71 \pm 0.43$ and $3.24 \pm 0.34 \mathrm{~cm}$, respectively) but these were characterized by a more complex architecture. That of DBVPG7019 showed a ruffed central hub surrounded by irregular radial spoke pattern and peripheral ring. That of $R$. toruloides CBS315 was characterized by a small elevated central hub, an evident radial spoke pattern and an irregular peripheral ring. $R$. mucilaginosa DBVPG6094 and $R$. toruloides CBS6016 produced MATs with diameter $\leq 3 \mathrm{~cm}$ with ruffled hub, radial spoke patterns, and jagged peripheral ring. R. glutinis CBS2366 MAT measured about $2 \mathrm{~cm}$ and was smooth. At higher agar percentages in YEPD, MAT size decreased while their density increased [48]. Thus, similar to S. cerevisiae, moisture and strength of the substrate affected MAT size and density. 

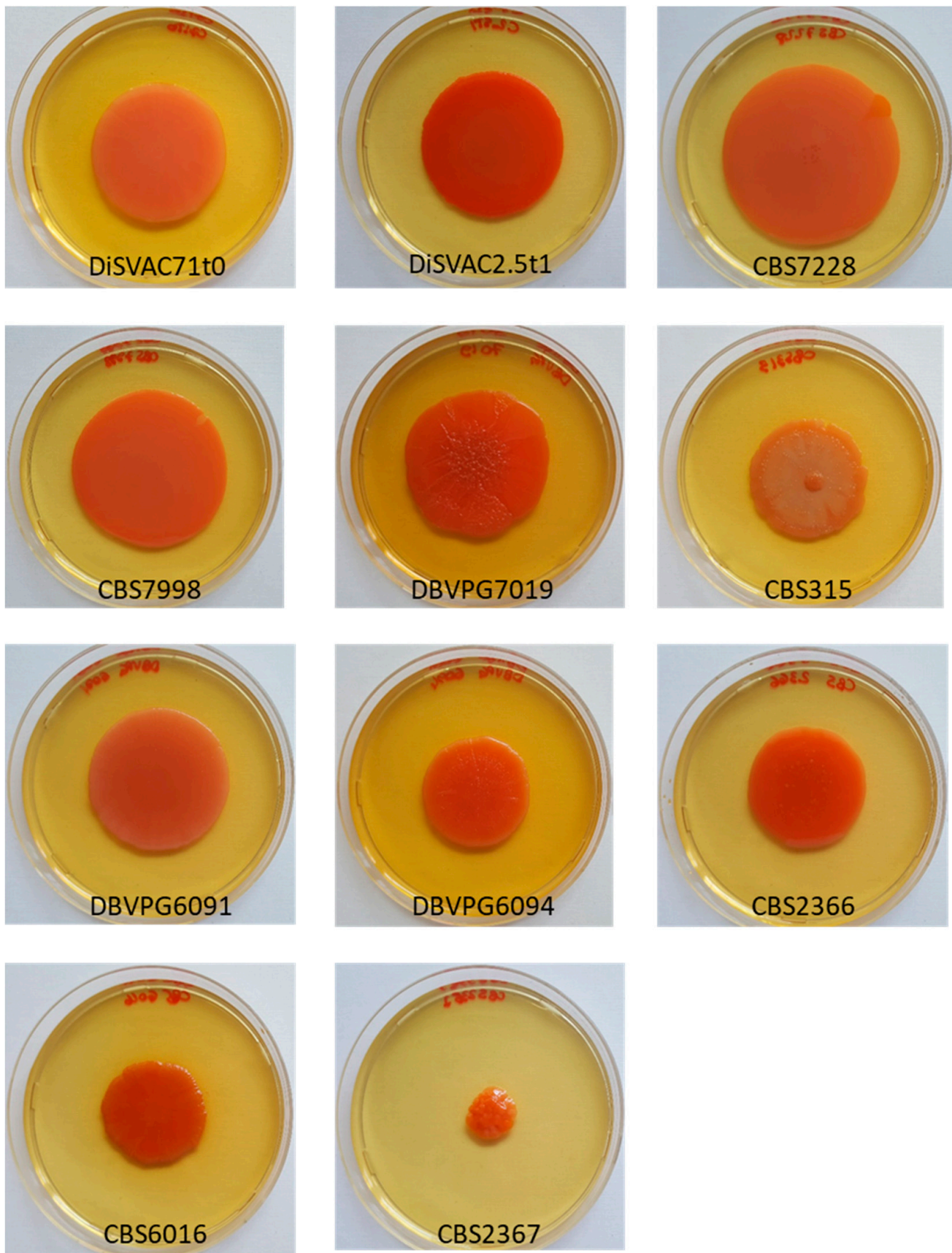

Figure 1. MAT morphology on $\mathrm{YEPD}_{0.3 \%}$. Cells growing in YEPD were washed, resuspended in sterile distilled water, and $5 \mu \mathrm{L}$ of each cell suspension were spotted on $\mathrm{YEPD}_{0.3 \%}$. After 15 days of incubation at $25^{\circ} \mathrm{C}$, plates were photographed with a digital camera. Results are representative of three independent replicates.

Cellular MAT formation involves cell-cell adhesion and adhesion to the surface of the growth medium. In S. cerevisiae, Flo11p is among the factors responsible for MATs formation [49] and architecture [50,51] but it is involved also in the adhesion to plastic surfaces [49]. The mechanisms implicated in adhesion to solid surfaces are scarcely characterized in Rhodotorula and Sporobolomyces. Buck and Andrews [20] reported that adhesion to polystyrene (PS) is mediated by the production of a thick layer of mucilage positively charged and localized over developing buds in $R$. toruloides.

Here, to gather further information on red yeast biodiversity in terms of biofilm forming ability, adhesion was evaluated on: polystyrene (PS), polypropylene (PP), and 
polyvinyl chloride (PVC). These three plastic materials are utilized for different purposes. PS is used mainly for foodservice containers; PP, which is characterized by high mechanical strength, is utilized in the production of laboratory (test tubes, beaker, centrifuge tubes) and medical devices (cannulas, syringes, oxygenators, hoses); and PVC is used for medical devices (catheters, prostheses, etc.) and for plumbing water systems. Thus, the 11 yeasts were grown in low glucose containing medium and adherence was tested on PS, PP, and PVC microplates. For this experiment, two strains of $S$. cerevisiae, namely UNISSM25 and UNISS3238-32 $\Delta$ flo11, were utilized as positive and negative controls of adhesion, respectively (Table 2). UNISSM25 is a wild flor strain, widely characterized for its biofilm forming ability [31], while UNISS3238-32 $\Delta$ flo11 is a non-biofilm-forming mutant [32,52].

Table 2. Adhesion to plastic materials.

\begin{tabular}{cccc}
\hline \multirow{2}{*}{ Strain } & \multicolumn{3}{c}{ Abs $_{\text {570 }}$ (Mean \pm Std) } \\
\cline { 2 - 4 } & PS & PP & PVC \\
\hline DBVPG6091 & $2.67 \pm 0.32$ & $3.43 \pm 0.10$ & $0.82 \pm 0.13$ \\
DBVPG6094 & $1.21 \pm 0.05$ & $1.32 \pm 0.07$ & $1.64 \pm 0.21$ \\
DBVPG7019 & $2.10 \pm 0.47$ & $0.88 \pm 0.13$ & $2.30 \pm 0.56$ \\
DiSVAC2.5t1 & $2.75 \pm 0.13$ & $2.93 \pm 0.32$ & $2.56 \pm 0.12$ \\
DiSVAC71t0 & $3.16 \pm 0.13$ & $3.17 \pm 0.06$ & $3.08 \pm 0.28$ \\
CBS2366 & $1.26 \pm 0.12$ & $1.47 \pm 0.15$ & $1.57 \pm 0.14$ \\
CBS2367 & $1.50 \pm 0.63$ & $2.55 \pm 0.30$ & $1.77 \pm 0.15$ \\
CBS6016 & $3.44 \pm 0.04$ & $3.40 \pm 0.04$ & $3.50 \pm 0.00$ \\
CBS315 & $2.18 \pm 0.33$ & $2.05 \pm 0.18$ & $1.85 \pm 0.13$ \\
CBS7228 & $2.11 \pm 0.14$ & $2.23 \pm 0.40$ & $2.14 \pm 0.32$ \\
CBS7998 & $0.88 \pm 0.32$ & $1.21 \pm 0.09$ & $1.70 \pm 0.35$ \\
UNISSM25 & $2.68 \pm 0.06$ & $2.71 \pm 0.12$ & $3.21 \pm 0.21$ \\
UNISS3238-32 $\Delta$ flo11 & $0.48 \pm 0.03$ & $1.02 \pm 0.12$ & $1.11 \pm 0.19$ \\
\hline
\end{tabular}

Notes: Data are mean \pm standard deviation of three independent experiments. UNISSM25 and UNISS3238-32 $\Delta$ flo11 were utilized as positive and negative controls of adhesion, respectively.

Results, reported in Table 2, show that some of the strains, although differing in the degree of adhesion, presented a consistent phenotype on the three plastic materials. Among these, $R$. mucilaginosa DiSVAC71t0 and $R$. toruloides CBS6016 showed the overall strongest adhesion with $\mathrm{Abs}_{570}>3$. This was higher than that of the positive control S. cerevisiae M25. R. mucilaginosa DiSVAC2.5t1 and S. oryzicola CBS7228, which displayed adhesion values in the range of those expressed by M25 ( $\left.\operatorname{Abs}_{570}>2\right)$, were followed by $R$. mucilaginosa DBVPG6094 and R. glutinis CBS2366 (Abs $570<2)$. The remaining strains presented a variable phenotype, depending on the plastic material. In particular, $R$. mucilaginosa DBVPG6091 proved strongly adhesive to PP, but it showed lower adhesion to PS and very weak adhesion to PVC. R. glutinis CBS2367 showed stronger adhesion to PP than to PS and PVC and R. glutinis CBS7998 showed very weak adhesion to PS. R. mucilaginosa DBVPG7019 showed $\mathrm{Abs}_{570}>2$ on PS and PVC and very low adhesion to PP while R. toruloides CBS315 was characterized by $\mathrm{Abs}_{570}$ around 2 on the three plastic materials.

\subsection{Invasive Growth and Temperature Growth Interval}

Invasive growth is described as the production of filaments that penetrate the surface of agar plates and resist to washing of the agar medium surface. This phenotype was evaluated in vitro on low glucose containing medium $\left(\mathrm{SCD}_{0.1 \%}\right)$ as suggested by [48]. On this medium, all strains, with the exception of CBS7228 and DiSVAC71t0, showed invasive growth with CBS6016 showing the strongest phenotype (Figure 2). Invasive growth has been associated with fruit decay in Pichia fermentans, thus raising the problem of the biological risk associated with the use of dimorphic yeasts as biocontrol agents [53]. Moreover, it is considered a putative virulence character in clinically relevant yeast $[54,55]$. Thus, while evaluating the growth temperature interval of these red yeasts, also temperatures compatible with human body infections were considered and the 11 yeast strains were 
tested for growth at 20, 25, 30, 37, and $40^{\circ} \mathrm{C}$. R. mucilaginosa DBVPG7019, DiSVAC71t0, DiSVAC2.5t1, $R$. toruloides CBS6016, CBS315, S. oryzicola CBS7228 grew at $20^{\circ} \mathrm{C}$ and all strains grew easily at $25^{\circ} \mathrm{C}$. CBS2366 and CBS2367 failed to grow at $30^{\circ} \mathrm{C}$ and none of them grew at 37 and $40{ }^{\circ} \mathrm{C}$ (Table 3), thus suggesting the incapability of these strains to infect humans [56].

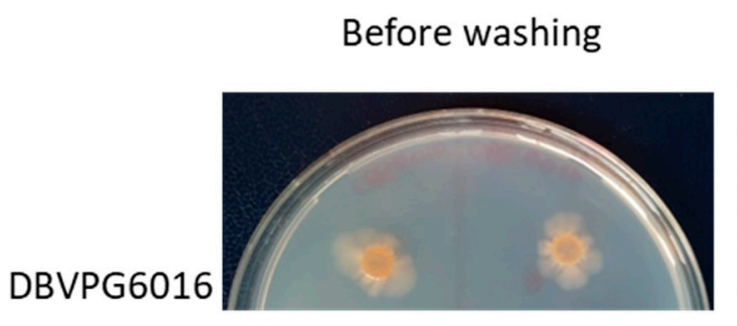

After washing
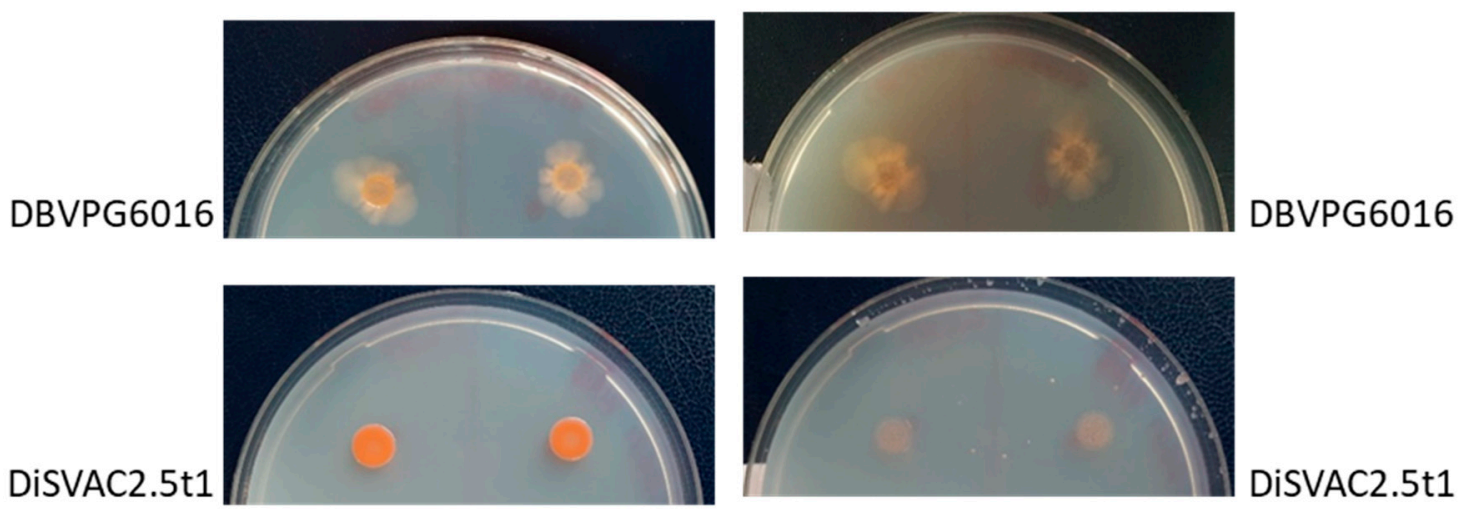

DiSVAC2.5t1
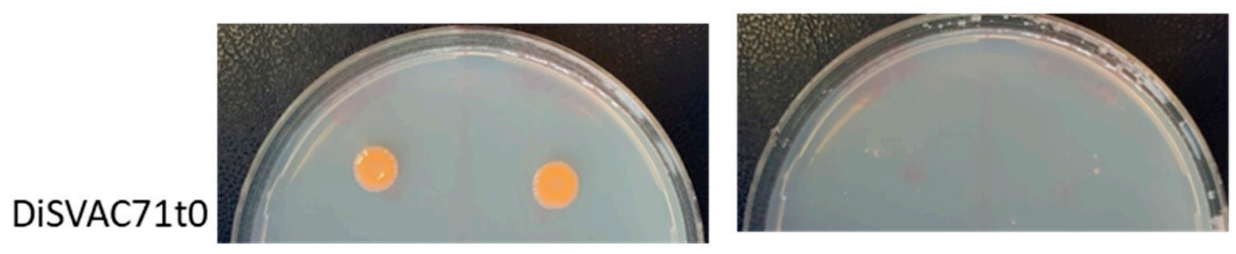

DiSVAC71t0
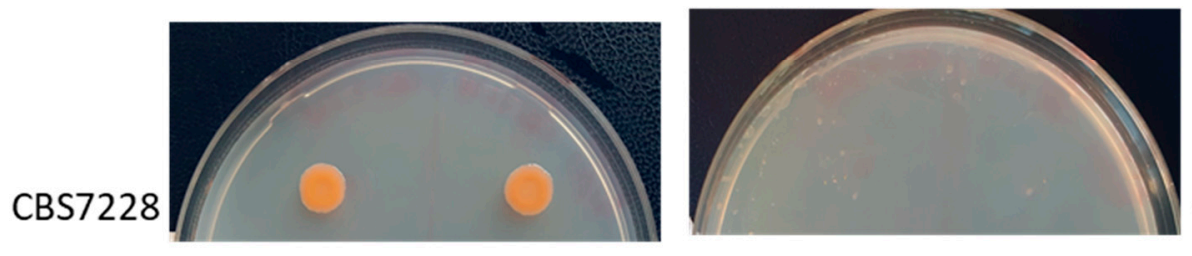

CBS7228
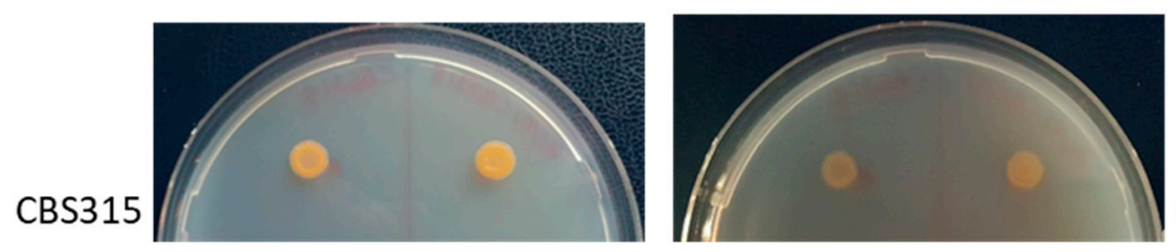

CBS315

Figure 2. Invasive growth of strains representative of different phenotypes. Cells exponentially growing in $\mathrm{SCD}_{2} \%$ were washed, resuspended in sterile distilled water, spotted on $\mathrm{SCD}_{0.1 \%}$, and incubated at $25{ }^{\circ} \mathrm{C}$ per 10 days. Petri dishes were photographed with a digital camera before and after washing with sterile distilled water. Results presented are representative of three independent replicates.

Table 3. Temperature growth interval.

\begin{tabular}{cccccc}
\hline \multirow{2}{*}{ Strain } & \multicolumn{5}{c}{ Temperature $\left({ }^{\circ} \mathbf{C}\right)$} \\
\cline { 2 - 6 } & $\mathbf{2 0}$ & $\mathbf{2 5}$ & $\mathbf{3 0}$ & $\mathbf{3 7}$ & $\mathbf{4 0}$ \\
\hline DBVPG7019 & + & + & + & - & - \\
\hline CBS7228 & + & + & + & - & - \\
\hline CBS315 & + & + & + & - & - \\
\hline CBS2366 & - & + & - & - & - \\
\hline DBVPG6094 & - & + & w & & - \\
\hline
\end{tabular}


Table 3. Cont.

\begin{tabular}{cccccc}
\hline \multirow{2}{*}{ Strain } & \multicolumn{5}{c}{ Temperature $\left({ }^{\circ} \mathbf{C}\right)$} \\
\cline { 2 - 6 } & $\mathbf{2 0}$ & $\mathbf{2 5}$ & $\mathbf{3 0}$ & 37 & $\mathbf{4 0}$ \\
\hline DBVPG6091 & - & + & + & - & - \\
\hline CBS7899 & - & + & + & - & - \\
\hline CBS2367 & - & + & - & - & - \\
\hline CBS6016 & + & + & w & - & - \\
\hline DiSVAC71t0 & + & + & + & - & - \\
\hline DiSVAC2.5t1 & + & + & + &
\end{tabular}

\subsection{Biocontrol Activity on Apple Fruit}

Once inoculated into wounds artificially inflicted to apple fruit and infected with P. expansum, the 11 strains proved highly diverse in terms of biocontrol activity. With the only exception of CBS2366, all the other strains presented significant reductions of the diameter of the lesions in respect to the control $(p<0.05)$. The most promising were R. mucilaginosa DiSVAC71t0 and S. oryzicola CBS7228 which determined more than $>50 \%$ reduction of P. expansum decay on apple. These were followed by R. mucilaginosa DBVPG6094 and DiSVAC2.5t1 which caused a decay reduction $\geq 40 \%$. R. mucilaginosa DBVPG6091 and DBVPG7019 and $R$. toruloides CBS6016 and CBS315 showed a percentage of decay reduction $>20<40$ and the remaining strains showed less than $20 \%$ reduction of $P$. expansum lesions on apple fruit (Figure 3). Other red yeasts reduced significantly the incidence of plant pathogenic fungi. For example, R. glutinis proved effective against Botrytis cinerea on strawberries and apples (US patent US5525132A) $[57,58]$ possibly due to the attachment capability of the antagonistic R. glutinis to B. cinerea [59]. R. glutinis was also applied in combination with rhamnolipids to be more efficacious against A. alternata infection in cherry tomato fruit than either agent alone [60].

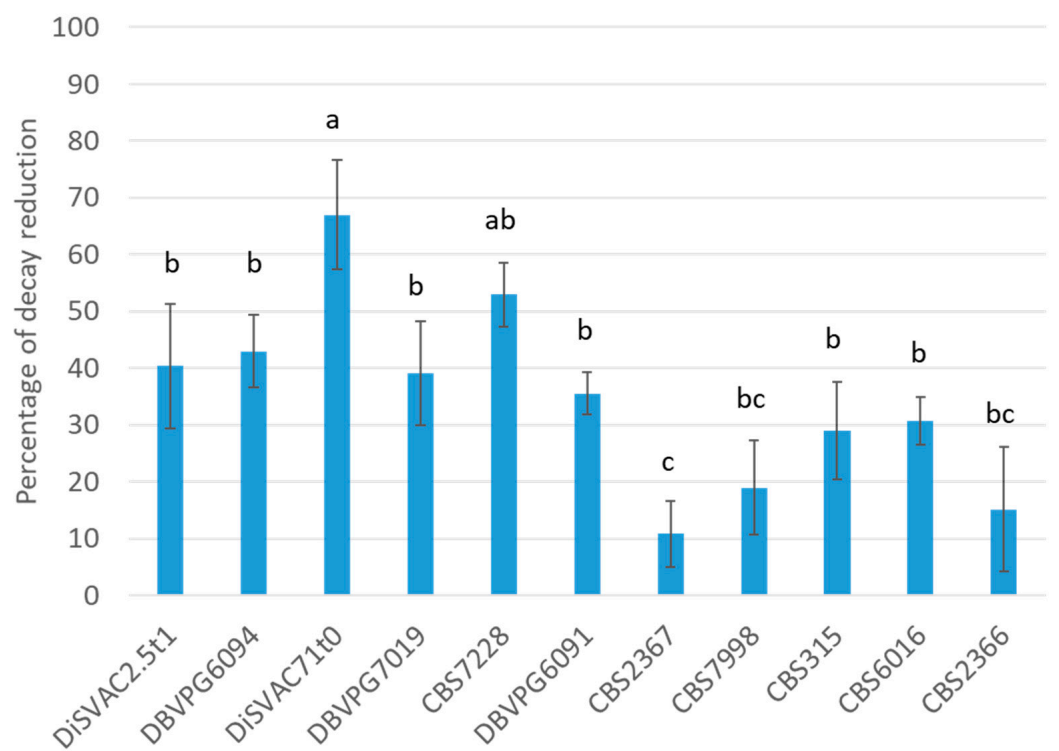

Figure 3. Biocontrol activity on apple fruit. Apple fruits were wounded (three wounds/fruit) along the equatorial region, inoculated with yeast cells and P. expansum, and stored in the dark at $26^{\circ} \mathrm{C}$ and $85 \pm 5 \%$ relative humidity for up to 7 days. The diameter of decayed tissue around each wound was measured at $48 \mathrm{~h}$ intervals to evaluate the incidence of $P$. expansum infection. Results are expressed as percentage of decay reduction (means \pm standard deviation of three independent replicates of three biological samples) with respect to the inoculated control. Same superscript letters indicate results not significantly different among strains $(p<0.05)$. 


\subsection{FAMD and Cluster Analysis of Phenotypic Data}

To summarize the information about the phenotypes studied and to allow the identification of red yeast strains and/or phenotypes for future works aimed at red yeasts exploitation in food biotechnological processes, FAMD followed by k-means cluster analyses were carried out (Figure 4A). Variables analyzed also included biomass and carotenoids production [26]. The average silhouette approach estimated the presence of 5 optimal clusters. Of these, cluster 4 aggregates most of the strains, while clusters 2 and 3 are each constituted by only one strain. In accordance with the contribution of the phenotypic variables to the first and second dimension (Figure 4B), strains grouped in cluster 5 (S. oryzicola CBS7228 and R. mucilaginosa DiSVAC2.5t1 and DiSVAC71t0) displayed the highest biocontrol activity ( $\geq 40 \%$ blue mold reduction) and among the strongest adhesion phenotypes on plastic materials (particularly on PVC), hence suggesting a possible means of high throughput in vitro selection for potentially effective biocontrol agents.

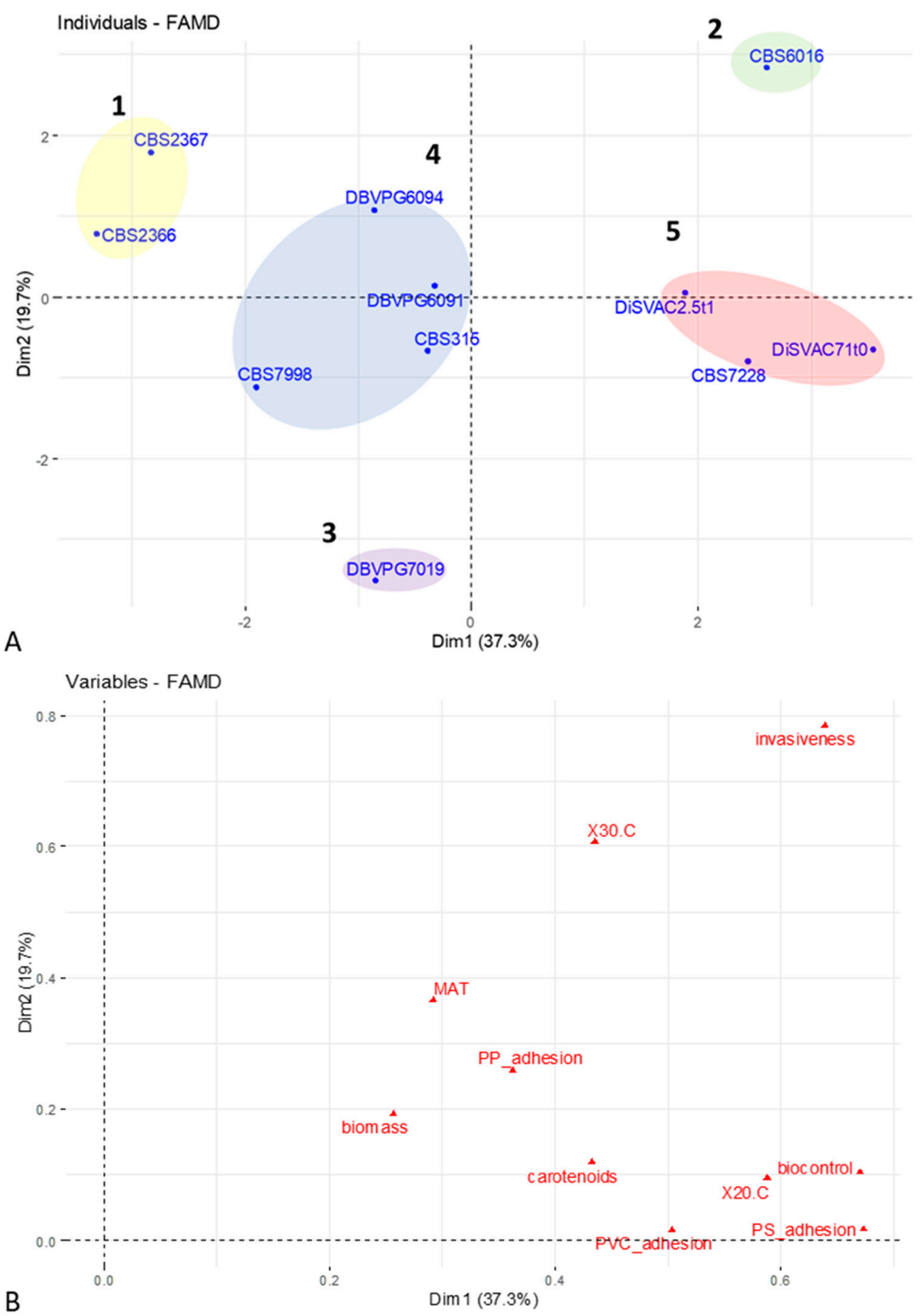

Figure 4. FAMD and cluster analysis of phenotypic data. (A): FAMD of the first two dimensions (total explained variance equal to 57\%). Individuals with similar profiles are close to each other on the factor map and are enclosed in ellipses of the same color, as determined after k-means clustering. (B): Plot of variables on the first two dimension (total explained variance equal to $57 \%$ ). 
As recently reviewed by [40], yeast biofilm formation in food and food processing plants could be considered as a positive or negative phenotype. Here, the high biofilm forming ability coupled with the high carotenoid content of the strains in cluster 5 suggests their possible utilization for the continuous production of carotenoids in bioreactors where yeast cells are immobilized on inert surfaces [61]. In addition, the high biomass obtained by growing these strains on glycerol suggests the use of these strains for the valorization of such by-products, thus increasing the sustainability of carotenoid production [26]. In this respect, the lack of invasiveness of CBS7228, together with its biocontrol activity and adhesion to plastic materials, makes this strain the most interesting for future analyses. Indeed, as already reported, invasiveness has been thought to contribute to yeast virulence and fruit decay [19]. Strain CBS6016 (cluster 2), while sharing many of the properties of the yeasts included in cluster 5, shows a higher invasiveness and is, thus, less suitable for the food sector. In cases such as those in which biocontrol activity should be associated to low biofilm forming ability and scarce invasiveness, strain DBVPG7019 (cluster 3) should be preferred for further characterizations. Finally, strains included in cluster 1 appear as the less interesting for biotechnological applications, given their inability to grow at 20 and $30^{\circ} \mathrm{C}$, and their reduced production of carotenoids and scarce biocontrol activity. Similarly, strains in cluster 4 seem to have a limited biotechnological potential as they show average values for what concerns MAT formation, adhesion on PVC, invasiveness, biocontrol activity, and carotenoid production.

\section{Conclusions}

Phenotypic analyses of eleven red yeasts of different origins suggested that a comprehensive characterization of these yeasts is mandatory to assess their potential use in food processes. Besides carotenoids production and biocontrol activities, also phenotypes not previously evaluated on red yeast are indeed essential for the identification of the most suitable biotechnological process for their exploitation. Particularly, biofilm formation and invasiveness should be carefully evaluated before selecting strains for continuous production of carotenoids or as biocontrol agents and feed supplements, respectively. In addition, the inability of strains to grow at a temperature compatible with human infection should be carefully determined. Finally, statistical analyses allowed the selection of yeast strains with interesting phenotypes for their further characterization and application in agri-food-related processes.

Author Contributions: Conceptualization, I.M., G.Z.; Methodology, I.M., S.Z., Q.M.; Formal Analysis, G.Z., M.G.F., C.M.; Investigation, G.Z., M.G.F.; Resources, I.M.; Data Curation, G.Z.; WritingOriginal Draft Preparation, G.Z., I.M.; Writing-Review \& Editing, M.B., S.Z., Q.M., I.M.; Supervision, I.M.; Funding Acquisition, I.M. All authors have read and agreed to the published version of the manuscript.

Funding: This work was partially granted by University of Sassari, "Fondo di Ateneo per la Ricerca 2019", (P.I I.M.). GZ gratefully acknowledges Sardinia Regional Government for the financial support of his research grant (Regional Operational Program of the European Social Fund (ROP ESF) 20142020-C.U.P. J86C18000270002).

Conflicts of Interest: The authors declare no conflict of interest.

\section{References}

1. Molla, G.; Motteran, L.; Piubelli, L.; Pilone, M.S.; Pollegioni, L. Regulation of D-amino acid oxidase expression in the yeast Rhodotorula gracilis. Yeast 2003, 20, 1061-1069. [CrossRef]

2. Csutak, O.; Stoica, I.; Vassu, T. Evaluation of production, stability and activity of biosurfactants from yeasts with application of bioremediation of oil polluted environment. Rev. Chim. 2012, 67, 973-977.

3. Johnson, E.A. Biotechnology of non-Saccharomyces yeasts-The basidiomycetes. Appl. Microbiol. Biotechnol. 2013, 97, 7563-7577. [CrossRef] [PubMed]

4. Moliné, M.; Libkind, D.; del Carmen Diéguez, M.; van Broock, M. Photoprotective role of carotenoids in yeasts: Response to UV-B of pigmented and naturally-occurring albino strains. J. Photochem. Photobiol. B Biol. 2009, 95, 156-161. [CrossRef] [PubMed] 
5. Fiedor, J.; Burda, K. Potential role of carotenoids as antioxidants in human health and disease. Nutrients 2014, 6, 466-488. [CrossRef] [PubMed]

6. Nishino, H.; Murakoshi, M.; Tokuda, H.; Satomi, Y. Cancer prevention by carotenoids. Arch. Biochem. Biophys. 2009, 483, 165-169. [CrossRef] [PubMed]

7. Hu, C.; Zhao, X.; Zhao, J.; Wu, S.; Zhao, Z.K. Effect of biomass hydrolysis by-products on oleaginous yeast Rhodosporidium toruloides. Biores. Technol. 2009, 100, 4843-4847. [CrossRef] [PubMed]

8. Li, R.; Zhang, H.; Liu, W.; Zheng, X. Biocontrol of postharvest gray and blue mold decay of apples with Rhodotorula mucilaginosa and possible mechanisms of action. Int. J. Food Microbiol. 2011, 146, 151-156. [CrossRef] [PubMed]

9. Zhang, H.; Ge, L.; Chen, K.; Zhao, L.; Zhang, X. Enhanced biocontrol activity of Rhodotorula mucilaginosa cultured in media containing chitosan against postharvest diseases in strawberries: Possible mechanisms underlying the effect. J. Agric. Food Chem. 2014, 62, 4214-4224. [CrossRef]

10. Zhang, H.; Wang, L.; Ma, L.; Dong, Y.; Jiang, S.; Xu, B.; Zheng, X. Biocontrol of major post-harvest pathogens on apple using Rhodotorula glutinis and its effects on post-harvest quality parameters. Biol. Control 2009, 48, 79-83. [CrossRef]

11. Ge, L.; Zhang, H.; Chen, K.; Ma, L.; Xu, Z. Effect of chitin on the antagonistic activity of Rhodotorula glutinis against Botrytis cinerea in strawberries and the possible mechanisms involved. Food Chem. 2010, 120, 490-495. [CrossRef]

12. Li, B.; Peng, H.; Tian, S. Attachment capability of antagonistic yeast Rhodotorula glutinis to Botrytis cinerea contributes to biocontrol efficacy. Front. Microbiol. 2016, 7, 601. [CrossRef]

13. Chen, J.; Li, B.; Qin, G.; Tian, S. Mechanism of $\mathrm{H}_{2} \mathrm{O}_{2}$-induced oxidative stress regulating viability and biocontrol ability of Rhodotorula glutinis. Int. J. Food Microbiol. 2015, 193, 152-158. [CrossRef]

14. Yan, F.; Xu, S.; Chen, Y.; Zheng, X. Effect of rhamnolipids on Rhodotorula glutinis biocontrol of Alternaria alternata infection in cherry tomato fruit. Postharvest Biol.Technol. 2014, 97, 32-33. [CrossRef]

15. Zhang, H.; Ma, L.; Turner, M.; Xu, H.; Zheng, X.; Dong, Y.; Jiang, S. Salicylic acid enhances biocontrol efficacy of Rhodotorula glutinis agains tpost-harvest Rhizopus rot of strawberries and the possible mechanisms involved. Food Chem. 2010, 122, 577-583. [CrossRef]

16. Filonow, A.B. Role of competition for sugars by yeasts in the biocontrol of gray mold of apple. Biocontrol Sci. Technol. 1998, 8, 243-256. [CrossRef]

17. Zheng, X.; Yang, Q.; Zhang, X.; Apaliya, M.T.; Ianiri, G.; Zhang, H.; Castoria, R. Biocontrol agents increase the specific rate of patulin production by Penicillium expansum but decrease the disease and total patulin contamination of apples. Front. Microbiol. 2017, 8, 1240. [CrossRef] [PubMed]

18. Droby, S.; Wisniewski, M.; Macarisin, D.; Wilson, C. Twenty years of postharvest biocontrol research: Is it time for a new paradigm? Postharvest Biol. Technol. 2009, 52, 137-145. [CrossRef]

19. Freimoser, F.M.; Rueda-Mejla, M.P.; Tilocca, B.; Migheli, Q. Biocontrol yeasts: Mechanisms and application. World J. Microbiol. Biotechnol. 2019, 35, 154. [CrossRef]

20. Buck, J.W.; Andrews, J.H. Localized, positive charge mediates adhesion of Rhodosporidiun toruloides to barley leaves and polystyrene. Appl. Environ. Microbiol. 1999, 65, 2179-2183. [CrossRef]

21. Pandin, C.; Le Coq, D.; Canette, A.; Symerich, S.; Briandet, R. Should the biofilm mode of life be taken into consideration for microbial biocontrol agents? Microbial Biotechnol. 2017, 10, 719-734. [CrossRef] [PubMed]

22. Raut, J.S.; Doke, S.K.; Karuppayil, S.M. Yeast biofilms in the context of human health and disease. In Yeast Diversity in Human Welfare; Satyanarayana, T., Kunze, G., Eds.; Springer: Singapore, 2017; pp. 57-82.

23. Parvu, M.; Paraschivescu, M.T. Feeding Rhodotorula rubra yeast in egg yolk pigmentation. Rom. Biotechnol. Lett. 2014, 19, 4-14.

24. Elwan, H.A.M.; Elnesr, S.S.; Abdallah, Y.; Hamdy, A.; El-Bogdady, A.H. Red yeast (Phaffia rhodozyma) as a source of astaxanthin and its impacts on productive performance and physiological responses of poultry. World's Poultry Sci. J. 2019, 75, 273-284. [CrossRef]

25. Camiolo, S.; Toome-Heller, M.; Aime, M.C.; Haridas, S.; Grigoriev, I.V.; Porceddu, A.; Mannazzu, I. An analysis of codon bias in six red yeasts species. Yeast 2018, 1-12. [CrossRef] [PubMed]

26. Cutzu, R.; Coi, A.; Rosso, F.; Bardi, L.; Ciani, M.; Budroni, M.; Zara, G.; Zara, S.; Mannazzu, I. From crude glycerol to carotenoids by using a Rhodotorula glutinis mutant. World J. Microbiol. Biotechnol. 2013, 29, 1009-1017. [CrossRef]

27. Deligios, M.; Fraumene, C.; Abbondio, M.; Mannazzu, I.; Tanca, A.; Addis, M.F.; Uzzau, S. Draft genome sequence of Rhodotorula mucilaginosa, an emergent opportunistic pathogen. Genome Announc. 2015, 3. [CrossRef] [PubMed]

28. Landolfo, S.; Ianiri, G.; Camiolo, S.; Porceddu, A.; Mulas, G.; Chessa, R.; Zara, G.; Mannazzu, I. CAR gene cluster and transcript levels of carotenogenic genes in Rhodotorula mucilaginosa. Microbiology 2018, 164, 78-87. [CrossRef]

29. Addis, M.F.; Tanca, A.; Abbondio, M.; Cutzu, R.; Biosa, G.; Pagnozzi, D.; Uzzau, S.; Mannazzu, I. Proteomic analysis of Rhodotorula mucilaginosa: Dealing with the issues of a non-conventional yeast. Yeast 2016, 33, 433-449. [CrossRef]

30. Reynolds, T.B.; Fink, G.R. Bakers' yeast, a model for fungal biofilm formation. Science 2001, 291, 878-881. [CrossRef]

31. Zara, G.; Mannazzu, I.; Sanna, M.L.; Orro, D.; Farris, G.A.; Budroni, M. Exploitation of the semi-homothallic life cycle of Saccharomyces cerevisiae for the development of breeding strategies. FEMS Yeast Res. 2008, 8, 1147-1154. [CrossRef] 
32. Bou Zeidan, M.; Zara, G.; Viti, C.; Decorosi, F.; Mannazzu, I.; Budroni, M.; Giovannetti, L.; Zara, S. L-histidine inhibits biofilm formation and FLO11-associated phenotypes in Saccharomyces cerevisiae flor yeasts. PLoS ONE 2014, 9, e112141. [CrossRef] [PubMed]

33. Le, S.; Josse, J.; Husson, F. FactoMineR: An R Package for Multivariate Analysis. J. Stat. Soft. 2008, 25, 1-18. [CrossRef]

34. Kassambara, A.; Mundt, F. factoextra: Extract and Visualize the Results of Multivariate Data Analyses. 2020. R Package Version 1.0.7. Available online: https:/ / CRAN.R-project.org/package=factoextra (accessed on 21 December 2020).

35. Kumamoto, C.A. A contact-activated kinase signals Candida albicans invasive growth and biofilm development. Proc. Natl. Acad. Sci. USA 2005, 102, 5576-5581. [CrossRef] [PubMed]

36. Tan, C.H.; Koh, K.S.; Xie, C.; Zhou, Y.; Williams, R.; Ng, W.J.; Rice, S.A.; Kjelleberg, S. The role of quorum sensing signalling in EPS production and the assembly of a sludge community into aerobic granules. ISME J. 2014, 8, 1186-1197. [CrossRef]

37. Gow, N.; van de Veerdonk, F.; Brown, A.; Netea, M.G. Candida albicans morphogenesis and host defence: Discriminating invasion from colonization. Nat. Rev. Microbiol. 2012, 10, 112-122. [CrossRef]

38. Abdallah, M.; Benoliel, C.; Drider, D.; Dhulster, P.; Chihib, N.-E. Biofilm formation and persistence on abiotic surfaces in the context of food and medical environments. Arch. Microbiol. 2014, 196, 453-472. [CrossRef]

39. Gomes, I.B.; Simões, M.; Simões, L. An overview on the reactors to study drinking water biofilms. Water Res. 2014, 62, 63-87. [CrossRef]

40. Zara, G.; Budroni, M.; Mannazzu, I.; Fancello, F.; Zara, S. Yeast biofilm in food realms: Occurrence and control. Worl. J. Microbiol. Biotechnol. 2020, 36, 134-145. [CrossRef]

41. Licitra, G.; Ogier, J.C.; Parayre, S.; Pediliggieri, C.; Carnemolla, T.M.; Falentin, H. Variability of bacterial biofilms of the "tina" wood vats used in the ragusano cheese-making process. Appl. Environ. Microbiol. 2007, 73, 6980-6987. [CrossRef]

42. Feofilova, E.P.; Galanina, L.A.; Sergeeva, Y.E.; Mysyakina, I.S. Strategies of food substrate colonization by mycelial fungi. Microbiology 2013, 82, 11-14. [CrossRef]

43. Giaouris, E.; Heir, E.; Hébraud, M.; Chorianopoulos, N.; Langsrud, S.; Møretrø, T.; Habimana, O.; Desvaux, M.; Renier, S.; Nychas, G.-J. Attachment and biofilm formation by foodborne bacteria in meat processing environments: Causes, implications, role of bacterial interactions and control by alternative novel methods. Meat Sci. 2014, 97, 298-309. [CrossRef] [PubMed]

44. Legras, J.-L.; Moreno-Garcia, J.; Zara, S.; Zara, G.; Garcia-Martinez, T.; Mauricio, J.C.; Mannazzu, I.; Coi, A.L.; Bou Zeidan, M.; Dequin, S.; et al. Flor Yeast: New Perspectives Beyond Wine Aging. Front. Microbiol. 2016, 7, 503. [CrossRef] [PubMed]

45. Ashraf, M.A.; Ullah, S.; Ahmad, I.; Qureshi, A.K.; Balkhair, K.S.; Abdur Rehman, M. Green biocides, a promising technology: Current and future applications to industry and industrial processes. J. Sci. Food Agric. 2014, 94, 388-403. [CrossRef] [PubMed]

46. Grujić, S.; Vasić, S.; Radojević, I.; Čomić, L.; Ostojić, A. Comparison of the Rhodotorula mucilaginosa biofilm and planktonic culture on heavy metal susceptibility and removal potential. Water Air Soil Pollut. 2017, 228, 73. [CrossRef]

47. Reynods, T. The Opi1p transcription factor affects expression of FLO11, mat formation, and invasive growth in Saccharomyces cerevisiae. Eukaryot. Cell 2006, 5, 1266-1275. [CrossRef] [PubMed]

48. Cullen, P.J. Biofilm/MAT assays for budding yeasts. Cold Spring Harb. Protoc. 2015, 2, 172-175.

49. Zara, G.; Zara, S.; Pinna, C.; Marceddu, S.; Budroni, M. FLO11 gene length and transcriptional level affect biofilm forming ability of wild flor strains of Saccharomyces cerevisiae. Microbiology 2009, 155, 3838-3846. [CrossRef]

50. Št'ovíček, V.; Váchová, L.; Begany, M.; Wilkinson, D.; Palková, Z. Global changes in gene expression associated with phenotypic switching of wild yeast. BMC Genomics 2014, 15, 136. [CrossRef]

51. Vopálenská, I.; St'ovícek, V.; Janderová, B.; Palkovà, Z. Role of distinct dimorphic transitions in territory colonizing and formation of yeast colony architecture. Environ. Microbiol. 2010, 12, 264-277. [CrossRef]

52. Zara, S.; Bakalinsky, A.T.; Zara, G.; Pirino, G.; Demontis, M.A.; Budroni, M. FLO11-based model for air-liquid interfacial biofilm formation by Saccharomyces cerevisiae. Appl. Environ. Microbiol. 2005, 71, 2934-2939. [CrossRef]

53. Giobbe, S.; Marceddu, S.; Scherm, B.; Zara, G.; Mazzarello, V.; Budroni, M.; Migheli, Q. The strange case of a biofilm-forming strain of Pichia fermentans which controls Monilinia brown rot on apple but is pathogenic on peach fruit. FEMS Yeast Res. 2007, 7 , 1389-1398. [CrossRef] [PubMed]

54. Saville, S.P.; Lazzell, A.L.; Monteagudo, C.; Lopez-Ribot, J.L. Engineered control of cell morphology in vivo reveals distinct roles for yeast and filamentous forms of Candida albicans during infection. Eukaryot. Cell 2003, 2, 1053-1060. [CrossRef] [PubMed]

55. Whiteway, M.; Oberholzer, U. Candida morphogenesis and host-pathogen interactions. Curr. Opin. Microbiol. 2004, 7, 350-357. [CrossRef] [PubMed]

56. Nally, M.C.; Pesce, V.M.; Maturano, Y.P.; Muñoz, C.J.; Combina, M.; Toro, M.E.; de Figueroa, L.I.C.; Vazquez, F. Biocontrol of Botrytis cinerea in table grapes by non-pathogenic indigenous Saccharomyces cerevisiae yeasts isolated from viticultural environments in Argentina. Postharvest Biol. Technol. 2012, 64, 40-48. [CrossRef]

57. Parafati, L.; Vitale, A.; Restuccia, C.; Cirvilleri, G. The effect of locust bean gum (LBG)-based edible coatings carrying biocontrol yeasts against Penicillium digitatum and Penicillium italicum causal agents of postharvest decay of mandarin fruit. Food Microbiol. 2016, 58, 87-94. [CrossRef] [PubMed]

58. Grzegorczyk, M.; Zarowska, B.; Restuccia, C.; Cirvilleri, G. Postharvest biocontrol ability of killer yeasts against Monilinia fructigena and Monilinia fructicola on stone fruit. Food Microbiol. 2017, 61, 93-101. [CrossRef] [PubMed] 
59. Grzegorczyk, M.; Szalewicz, A.; Żarowska, B.; Połomska, X.; Watorek, W.; Wojtatowicz, M. Microorganisms in biological control of phytopathogenic fungi. Acta Sci. Pol. Biotechnol. 2015, 14, 19-42.

60. Liu, J.; Sui, Y.; Wisniewski, M.; Liu, Y. Review: Utilization of antagonistic yeasts to manage postharvest fungal diseases of fruit. Int. J. Food Microbiol. 2013, 167, 153-160. [CrossRef]

61. Taavoni, S.; Habibi, A.; Varmira, K.; Alipour, S. Kinetics of continuous production of $\beta$-carotene in an airlift bioreactor. Asia-Pac. J. Chem. Eng. 2018, 13, e2160. [CrossRef] 